\title{
Population Dynamics Modeling of Arapaima gigas
}

\author{
Eliane dos Santos de Souza COUTINHO ${ }^{1}$, Luiz BEVILACQUA², Helder Lima de QUEIROZ ${ }^{3}$
}

\begin{abstract}
Pirarucu (Arapaima gigas) has been of the most important natural fishing resources of the Amazon region. Due to its economic importance, and the necessity to preserve the species hand, field research concerning the habits and behavior of the pirarucu has been increasing for the last 20 years. The aim of this paper is to present a mathematical model for the pirarucu population dynamics considering the species peculiarities, particularly the male parental care over the offspring. The solution of the dynamical systems indicates three possible equilibrium points for the population. The first corresponds to extinction; the third corresponds to a stable population close to the environmental carrying capacity. The second corresponds to an unstable equilibrium located between extinction and full use of the carrying capacity. It is shown that lack of males' parental care closes the gap between the point corresponding to the unstable equilibrium and the point of stable non-trivial equilibrium. If guarding failure reaches a critical point the two points coincide and the population tends irreversibly to extinction. If some event tends to destabilize the population equilibrium, as for instance inadequate parental care, the model responds in such a way as to restore the trajectory towards the stable equilibrium point avoiding the route to extinction. The parameters introduced to solve the system of equations are partially derived from limited but reliable field data collected at the Mamirauá Sustainable Development Reserve (MSDR) in the Brazilian Amazonian Region.
\end{abstract}

KEY WORDS: Pirarucu (Arapaima gigas), population dynamics, Mamirauá, Mathematical Modeling

\section{Modelagem da Dinâmica Populacional de Arapaima gigas}

\section{RESUMO}

Pirarucu (Arapaima gigas) tem sido um dos mais importantes recursos pesqueiros naturais da Amazônia. Devido à sua importância econômica, por um lado, e a necessidade de preservar a espécie, por outro lado, o domínio da investigação relativa a hábitos e comportamento do pirarucu tem sido crescente nos últimos 20 anos. O objetivo deste trabalho é apresentar um modelo matemático para a dinâmica populacional do pirarucu considerando as peculiaridades da espécie, particularmente o cuidado parental do macho sobre seus descendentes. A solução dos sistemas dinâmicos indicaram três possíveis pontos de equilíbrio para a população. O primeiro corresponde à extinção; o terceiro corresponde a uma populaçáo estável próxima da capacidade suporte do ambiente. O segundo corresponde a um equilíbrio instável localizado entre a extinção e a capacidade suporte do ambiente. Foi mostrado que a falta do cuidado parental de machos aproxima o ponto que corresponde ao equilíbrio instável e o ponto de equilíbrio estável não trivial. Se a falta de cuidado dos machos alcança um ponto crítico, os dois pontos coincidem e a população tende irreversivelmente à extinção. Os parâmetros introduzidos para resolver o sistema de equaçóes foram derivados parcialmente de limitados, mas confiáveis dados de campo coletados na Reserva de Desenvolvimento Sustentável Mamirauá (RDSM) na Amazônia brasileira.

PALAVRaS-CHAVE: Pirarucu (Arapaima gigas), Dinâmica Populacional, Mamirauá, Modelagem Matemática.

\footnotetext{
1 Universidade Católica de Petrópolis. E-mail: eliane.coutinho@ucp.br

2 Universidade Federal do Rio de Janeiro. E-mail: bevilacqua@coc.ufrj.br

${ }^{3}$ Instituto de Desenvolvimento Sustentável Mamirauá. E-mail: hqueiroz@ufpa.br
} 


\section{INTRODUCTION}

Living mainly in white water lakes in the Amazonian floodplains, the várzea (Queiroz, 2000), Pirarucu (Arapaima gigas) is today one of the most important fishing resources in the Amazon region. Arapaima economic importance and preservation of the Amazonian ecosystem in equilibrium as well, justifies the growing attention given to field research concerning the habits and behavior of Arapaima for the last 20 years (Queiroz, 1997, Queiroz \& Sardinha, 1999; Castello, 2004; Hrbek T. et alli, 2005; Godinho et alli, 2005; Castello, 2008). To the better of our knowledge, field observations, however, have not yet been used as input for mathematical models that could add important information to the population dynamics of that species. This paper intends to bridge this gap with a model that could be partially tested in protected areas free from undesirable human intervention.

In order to set up the model it is necessary to consider the fundamental aspects of the Arapaima reproductive system (Imbiriba, 1994; Queiroz, 2000). To take into account all the details involving the reproduction process and the stages of the fish life cycle would make the model excessive complex and almost impossible to test due to the lack of biological information. Alternatively, using classical simple models would miss important characteristics proper to this species and no valuable information would be obtained. The present approach can be considered as laying in-between these two extremes. We have selected the most important characteristics of the Arapaima life cycle and designed a model that could represent sequentially the interaction between two different life stages.

For the present analysis the Arapaima lifespan can be divided into four stages representing four different biological periods: fertilized eggs, larvae/post-larvae, juvenile and adult fish. (Figure 1)

The main facts that have steered the definition of the dynamical system can be summarized as follows:

Choice of the partner is a female initiative. Mating is determined by male's color intensity which is somehow associated with the capacity for nest building and the ability to protect newborns (Queiroz \& Sardinha, 1999; Queiroz, 2000). Non-copulatory spawning is observed among this species. The fertilized eggs after spawning constitutes the first cycle. Approximately after seven to ten days fertilized eggs hatch into larvae.

Larvae and post-larvae remain under males protection till they become young fishes strong enough to protect themselves from external threatens (Fontenele, 1948). Larvae/post-larvae population constitutes the second life cycle.

The third cycle corresponds to the juvenile phase characterized by Arapaima total length less than $165 \mathrm{~cm}$ and sexual immaturity.

The fourth cycle corresponds to maturity as soon as the adult fishes are able to mate and reproduce, which happens when the animals are around five years old (Queiroz, 2000).

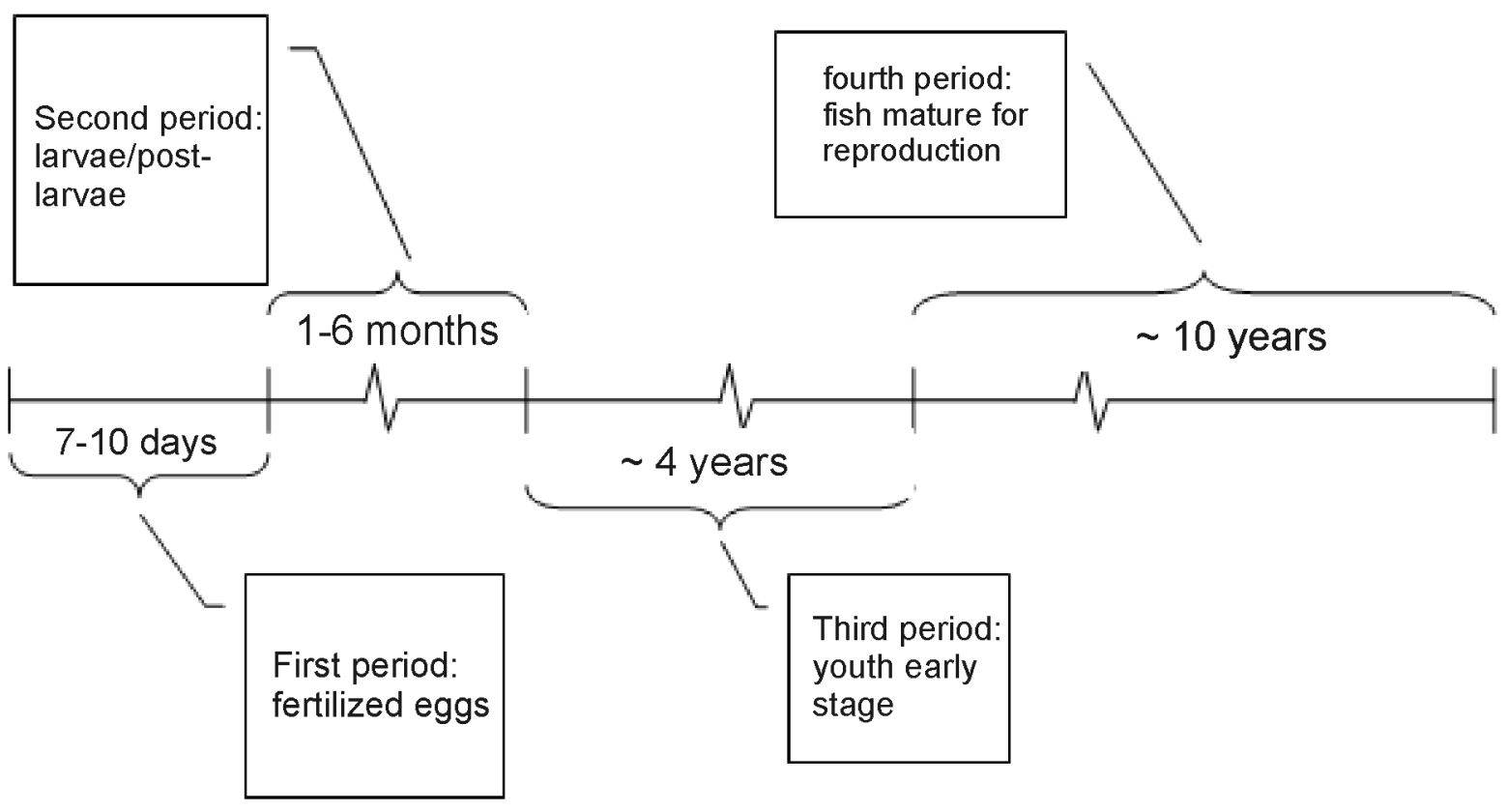

Figure 1 - Arapaima's life span divided into four characteristic periods 
A model devised to simulate the population dynamics of this species should, as much as possible, take into account the peculiarities characterizing each one of the four periods mentioned above. The offspring protection by males is a major characteristic of the second life cycle to be introduced in the model. Indeed, the lack of male protection introduces a new mortality coefficient to be added to that appearing in the classical population dynamics formulation. The larvae are kept under male's protection for about 12 weeks, or maybe more (Queiroz, 2000). For modeling purposes this period will be extend up to twelve months. This adjustment will not introduce any significant perturbation in the system.

As will be explained in the next section the second and third life periods will be lumped into a single one. This will simplify the analysis while keeping the influence of the male surveillance present in the population dynamics.

\section{MATHEMATICAL MODEL}

Five independent variables associated to the four life periods described in the previous section are needed to write the equations for the Arapaima population dynamics. Let us call these variables $\mathrm{g}_{1}, \mathrm{~g}_{2}, \hat{\mathrm{g}}_{2}, P$ and $Q$ representing respectively fertilized eggs, larvae/post larvae, juveniles (male plus female), adult males and adult females belonging to the same generation. In other words those variables correspond to different stages of a same primitive cohort.

In principle it is convenient to segregate male and female because adult males are genetically conditioned to protect the larvae/ post-larvae, which is not shared with adult females.

The population variation within the time interval $\Delta t$ associated with the different life cycles as illustrated in the Fig. 2 can now be defined:

$\Delta \mathrm{g}_{1}$ : variation of the number of fertilized eggs

$\Delta \mathrm{g}_{2}$ : variation of the larvae/post-larvae population originated from $\Delta \mathrm{g}_{1}$

$\Delta \hat{\mathrm{g}}_{2}$ : variation of the juvenile Arapaima population corresponding to the contribution of the previous stage $\Delta \mathrm{g}_{2}$

$\Delta \mathrm{P}, \Delta \mathrm{Q}$ : variation of the adult fish population, male and female respectively, corresponding to the contribution of the previous stage $\Delta \hat{\mathrm{g}}_{2}$

It is important to remark that mortality due to the lack of proper parental care is isolated here from the other natural causes. Introducing a particular term to take into account the effect of an ineffective parental care on the population dynamics may provide important information about the consequences of uncontrolled fishing activity. As it will be seen in the sequel it was possible to devise an analytical expression that represents satisfactorily the impact of the parental care on the population fluctuations.

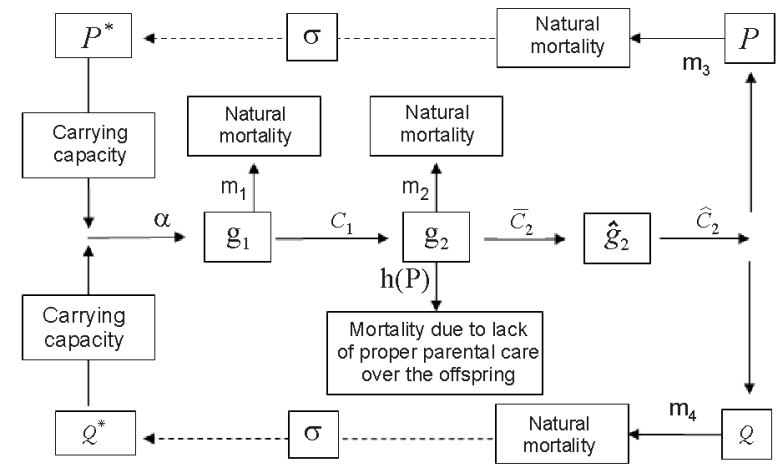

Figure 2 - Block diagram depicting the relations among the variables in the system and the respective life periods.

The variation of the quantity of fertilized eggs $\Delta \mathrm{g} 1$ is proportional to $a_{1} a_{2} \bar{P} \bar{Q}$ that is, a function of the current population composed by fishes of several generations ready to reproduce.

The parameter $a_{1}$ is the probability of successful fertilization per male per year:

$a_{1}=$ (probability of successful egg fertilization) $/$ (male) (year)

The parameter $a_{2}$ represents the spawning efficacy per female. This parameter takes also into account the fraction of females participating in the reproductive cycle. Then:

$a_{2}=($ number of dropped eggs) $/($ female $)$

Field observations have shown that the number of adult fishes and lake size are correlated (Castello, 2004). It is expected that the population reaches an upper limit which is a function of the area of a standard lake provided that the fundamental means of subsistence are kept equivalent for all lakes. Recent population density data of Arapaima gigas in Amazonian lakes (Arantes et alli, 2007) suggest that the normalized carrying capacity, that is the upper limit of the population, can be estimated as 10 adults/ha, which was similar to that capacity previously estimated by Queiroz (2000).

Let us call $\bar{k}$ the total carrying capacity. Therefore the growth rate of fertilized eggs is limited by the factor $\{1-(\bar{P}+\bar{Q}) / \bar{k}\}$. Therefore the effective increment of fertilized eggs per unit of time is $a_{1} a_{2} \bar{P} \bar{Q}\{1-(\bar{P}+\bar{Q}) / \bar{k}\}$. The variation $\Delta \mathrm{g}_{1}$ of the number of fertilized eggs can now be written:

$\Delta g_{1}=a_{1} a_{2} \bar{P} \bar{Q}\left(1-\frac{\bar{P}+\bar{Q}}{\bar{k}}\right) \Delta t-c_{1} g_{1} \Delta t-m_{1} g_{1} \Delta t$ 
Recalling that the larvae/post-larvae population $g_{2}$ belongs to the second life period and therefore are under males' protection, the variation $\Delta \mathrm{g}_{2}$ can be written as:

$$
\Delta g_{2}=c_{1} g_{1} \Delta t-\bar{h}(P) g_{2} \Delta t-\bar{c}_{2} g_{2} \Delta t-\bar{m}_{2} g_{2} \Delta t
$$

The contribution to growth is clearly the migration from the previous period given by $c_{1} g_{1} \Delta t$ and the three terms associated with the removal rate are:

$\bar{m}_{2} g_{2} \Delta t$ corresponding to natural mortality.

$\bar{c}_{2} g_{2} \Delta t$ corresponding to recruitment from the larvael post-larvae cycle to the juvenile phase.

$\bar{h}(P) g_{2} \Delta t$ corresponding to mortality induced by lack of proper male parental care.

With: (year)

$\bar{c}_{2}$ : (fraction of larvae migrating to the juvenile stage)/

$\bar{m}_{2}$ : (larvae/post-larvae mortality)/ (year)

The function $\bar{h}(P)$ represents the relative fraction of larvae/post-larvae lost due to lack of protection per unit of time.

The derivation of the population variation $\Delta \hat{g}_{2}$ corresponding to the next stage in the complete life cycle follows the same reasoning. It is easily obtained:

$$
\Delta \hat{g}_{2}=\bar{c}_{2} g_{2} \Delta t-\hat{c}_{2} \hat{g}_{2} \Delta t-\hat{m}_{2} \hat{g}_{2} \Delta t
$$

Where $\hat{c}_{2}$ is the recruitment rate from the juvenile phase to the adult phase and $\hat{m}_{2}$ the mortality rate of Arapaima juveniles.

Finally the fourth and fifth differential equations are straightforward. Since there is no biological bias for larvae to develop into females or males we will consider the recruitment rate to be the same for males and females that is $k_{2} / 2$ for both sexes. Therefore:

$$
\begin{aligned}
& \Delta P=\frac{1}{2} \hat{c}_{2} \hat{g}_{2} \Delta t-m_{3} P \Delta t \\
& \Delta Q=\frac{1}{2} \hat{c}_{2} \hat{g}_{2} \Delta t-m_{4} Q \Delta t
\end{aligned}
$$

Where $m_{3}$ and $m_{4}$ are male and female mortality rates respectively.

The first variation $\Delta \mathrm{g}_{1}$ involves the current population $\bar{P}$ and $\bar{Q}$. For our system, however, the relevant variables are $P$ and $Q$ which are fractions of the current stock, respectively $\bar{P}$ and $\bar{Q}$, derived from the primitive cohort. It is known that the Arapaima breeding aptitude is reached when the fish is about five years old. Let $\sigma \approx L F-5$ where $L F$ is the average Arapaima's lifespan expressed in years then we may write
$\bar{P}=\sigma P$ and $\bar{Q}=\sigma Q$. The variation $\Delta \mathrm{g}_{1}$ as function of $P$ and $Q$ then reads:

$\Delta g_{1}=\sigma^{2} a_{1} a_{2} P Q\left(1-\frac{(P+Q) \sigma}{\bar{k}}\right) \Delta t-c_{1} g_{1} \Delta t-m_{1} g_{1} \Delta t$

Note that, if $\bar{k}$ is the total carrying capacity of some specific lake, then the share in the current stock of a single cohort that has reached maturity is $k=\bar{k} / \sigma$. Therefore the growth rate of fertilized eggs corresponding to a single generation is limited by the factor $\{1-(P+Q) / k\}=\{1-(\bar{P}+\bar{Q}) / \bar{k}\}$.

The set of differential equations representing the Arapaima's population dynamics can now be written:

$\frac{d g_{1}}{d t}=a P Q\left(1-\frac{P+Q}{k}\right)-c_{1} g_{1}-m_{1} g_{1}$

$\frac{d g_{2}}{d t}=c_{1} g_{1}-\bar{h}(P) g_{2}-\bar{c}_{2} g_{2}-\bar{m}_{2} g_{2}$

$\frac{d \hat{g}_{2}}{d t}=\bar{c}_{2} g_{2}-\hat{c}_{2} \hat{g}_{2}-\hat{m}_{2} \hat{g}_{2}$

$\frac{d P}{d t}=\frac{1}{2} \hat{c}_{2} \hat{g}_{2}-m_{3} P$

$\frac{d Q}{d t}=\frac{1}{2} \hat{c}_{2} \hat{g}_{2}-m_{4} Q$

The third life period doesn't bring any useful information for the purpose of the present model. In order to simplify the system of equations we introduce the following hypothesis:

$\hat{g}_{2}=\varepsilon g_{2}$

The parameter $\varepsilon$ is constant. That is, the number of young fishes is a time independent linear function of the number of larvae/post-larvae. Field observations indicate that $\varepsilon$ is a very small parameter. This means that there is a substantial loss in the transition from larvae/post-larvae to juvenile fishes. With this assumption the equation $(2-c)$ reads:

$\varepsilon \frac{d g_{2}}{d t}=\bar{c}_{2} g_{2}-\varepsilon \hat{c}_{2} g_{2}-\varepsilon m_{2} g_{2}$

Adding this equation to equation (2-b) the parameter $\overline{\boldsymbol{c}}_{2}$ is eliminated and we obtain:

$\frac{d g_{2}}{d t}=\frac{1}{1+\varepsilon}\left[c_{1} g_{1}-h(P) g_{2}-\varepsilon \hat{c}_{2} g_{2}-\left(\bar{m}_{2}+\varepsilon \hat{m}_{2}\right) g_{2}\right]$

Now since $\varepsilon$ is small we may write:

$\frac{d g_{2}}{d t}=c_{1} g_{1}-h(P) g_{2}-c_{2} g_{2}-m_{2} g_{2}$

Where: $c_{2}=\varepsilon \hat{c}_{2}$ and $m_{2}=\bar{m}_{2}+\varepsilon \hat{m}_{2}$ 
The set of differential equations (2) then reduces to:

$\frac{d g_{1}}{d t}=a P Q\left(1-\frac{P+Q}{k}\right)-c_{1} g_{1}-m_{1} g_{1}$

$\frac{d g_{2}}{d t}=c_{1} g_{1}-\bar{h}(P) g_{2}-c_{2} g_{2}-m_{2} g_{2}$

$\frac{d P}{d t}=\frac{1}{2} c_{2} g_{2}-m_{3} P$

$\frac{d Q}{d t}=\frac{1}{2} c_{2} g_{2}-m_{4} Q$

Where $a=\sigma^{2} a_{1} a_{2}$

There is no evidence that under normal environmental conditions the mortality indices $m_{3}$ and $m_{4}$ should be different. This could happen if fishing would be allowed and capture preference - male or female - could be clearly detected. However this first approach disregards fishing activity. The population dynamics developed in this section is intended to simulate a fish population living in natural protected reserves, free from human intervention or other adverse physical or biological influences which could segregate males and females. Then $P=Q$ and the equation (4-d) is superfluous.

The equilibrium solutions are obtained for $d g_{1} / d t=d g_{2} /$ $d t=d P / d t=0$. Introducing these conditions in the system (4) the following relations are obtained:

$$
\left[-\left(P^{*}\right)^{2}+\frac{k}{2} P^{*}-\frac{k}{2 a}\left(1+\frac{m_{1}}{c_{1}}\right)\left(1+\frac{m_{2}}{c_{2}}\right) m_{3}-\frac{k}{2 a} \frac{m_{3}}{c_{2}}\left(1+\frac{m_{1}}{c_{1}}\right) \bar{h}(P)\right] P^{*}=0 \quad \text { (5-a) }
$$$$
g_{2}^{*}=\frac{2 m_{3}}{c_{2}} P^{*}
$$

$g_{1}^{*}=\frac{2 m_{3}}{c_{2} c_{1}}\left[\bar{h}\left(P^{*}\right)+c_{2}+m_{2}\right] P^{*}$

Here the set $\left\{g_{1}^{*}, g_{2}^{*}, P^{*}\right\}$ represents a general equilibrium solution. From $(5-a)$ it is evident that there are three possible equilibrium solutions.

Clearly $P_{1}^{*}=0\left(Q_{1}^{*}=0\right)$ is a solution. This equilibrium solution corresponds to extinction. The other two are given by the roots of the transcendent equation:

$-\left(P^{*}\right)^{2}+\frac{k}{2} P^{*}-\frac{k}{2 a}\left(1+\frac{m_{1}}{c_{1}}\right)\left(1+\frac{m_{2}}{c_{2}}\right) m_{3}=\frac{k}{2 a} \frac{m_{3}}{c_{2}}\left(1+\frac{m_{1}}{c_{1}}\right) \bar{h}\left(P^{*}\right)$

The corresponding values of $g_{1}^{*}$ and $g_{2}^{*}$ are obtained respectively from (5-b) and (5-c).

For flawless male parental care, i.e. $\bar{h}(P)=0$, the non trivial equilibrium solutions are the roots of the second order equation obtained from (5) setting $\bar{h}\left(P^{*}\right)=0$. For this particular case the other two, non vanishing, equilibrium solutions are:

$$
P_{2,3}^{*}=\frac{k}{4}\left\{1 \pm\left[1-\frac{16}{k a}\left(1+\frac{m_{1}}{c_{1}}\right)\left(1+\frac{m_{2}}{c_{2}}\right) m_{3}\right]^{1 / 2}\right\}
$$

The roots $P_{2}^{*}$ and $P_{3}^{*}$ must be real if the model response is supposed to simulate real cases. Then, as can be deduced immediately from equation (6-b), the following condition must be satisfied:

$$
\frac{16}{k a}\left(1+\frac{m_{1}}{c_{1}}\right)\left(1+\frac{m_{2}}{c_{2}}\right) m_{3}<1
$$

given that the equilibrium points $P_{2}^{*}$ and $P_{3}^{*}$ must remain inside the interval:

$$
0<P_{2}<P_{3}<\frac{k}{2}
$$

This is the expected result because the total population $(P+Q)$ is bounded by the environment carrying capacity $k$ and the roots must be real and positive.

Still considering the case of fully successful parental care over the larvae by adult males, that is $h(P)=0$, and having in mind that obviously $g_{1}^{*}>g_{2}^{*}>P^{*}$ the following inequalities are obtained from equations $(5-b, c)$ :

$\frac{2 m_{3}}{c_{2}}>1$

$$
m_{2}>c_{1}-c_{2}
$$

The inequalities $(7-a, b, c)$ are very useful for parameter estimation purposes as will be seen in the next section.

The sign of the real part of the Eigenvalue of the Jacobian matrix $J$, defined below, indicates if the solution in the neighborhood of an equilibrium point is stable or unstable.

$$
J=\left[\begin{array}{lll}
\frac{\partial F_{1}^{*}}{\partial g_{1}} & \frac{\partial F_{1}^{*}}{\partial g_{2}} & \frac{\partial F_{1}^{*}}{\partial P} \\
\frac{\partial F_{2}^{*}}{\partial g_{1}} & \frac{\partial F_{2}^{*}}{\partial g_{2}} & \frac{\partial F_{2}^{*}}{\partial P} \\
\frac{\partial F_{3}^{*}}{\partial g_{1}} & \frac{\partial F_{3}^{*}}{\partial g_{2}} & \frac{\partial F_{3}^{*}}{\partial P}
\end{array}\right]
$$

$F_{1}^{*}, F_{2}^{*}, F_{3}^{*}$ stay for the terms on the right hand side of the equations $4 \mathrm{a}, 4 \mathrm{~b}, 4 \mathrm{c}$ respectively. The terms in the matrix (8) are the derivatives of $F_{i}(\mathrm{i}=1,2,3)$ evaluated at the equilibrium points $\left\{g_{1}^{*}, g_{2}^{*}, P^{*}\right\}$. A detailed discussion of the stability of a dynamical system falls out of the scope of this paper and can be found in the specialized literature (Hirsh et alli, 2004; Guckenheimer et alli, 2002). A detailed analysis of the stability of the solutions of the differential equations system (4) can be found in [Cassiano et alli, 2007]. 


\section{SIMULATION OF THE Arapaima POPULATION DYNAMICS.}

As explained above under undisturbed ideal environmental conditions the set of differential equations (4) can be rewritten under the reduced form:

$$
\begin{aligned}
& \frac{d g_{1}}{d t}=a P Q\left(1-\frac{P+Q}{k}\right)-c_{1} g_{1}-m_{1} g_{1} \\
& \frac{d g_{2}}{d t}=c_{1} g_{1}-c_{2} g_{2}-m_{2} g_{2} \\
& \frac{d P}{d t}=\frac{1}{2} c_{2} g_{2}-m_{3} P
\end{aligned}
$$

With $P=Q$ and $\mathrm{a}=\sigma^{2} \mathrm{a}_{1} \mathrm{a}_{2}$. The term $\bar{h}(P)$ was dropped from (9-b) because in this section the male's parental care over the larvae will be considered ideal.

The determination of the parameters introduced in the derivation of the system above can not be ignored if a numerical solution is to be achieved. This is maybe the critical point of the formulation since the available data and field observations are yet insufficient to provide a complete set which would allow the determination of all parameters in (9). On the other hand, even with a crude estimation of certain parameters, the analytical results may provide useful information to guide future field experiments and data collection, particularly if the output is consistent with the overall behavior observed in some of the lakes of the Amazonian region.

Even though the results presented here have to be considered as a first approximation of the population dynamics, the simulations lead to plausible solutions as it will be seen later.

Field observations carried out at the Mamirauá Sustainable Development Reserve (Queiroz, 2000) allows the evaluation of the ratios (number of larvae)/(fertilized eggs) and (number of fertilized eggs)/(number of adults) provided that the stable equilibrium is reached, namely:

$$
\begin{aligned}
& \frac{g_{2}^{*}}{g_{1}^{*}} \approx \frac{1}{135} \\
& g_{2}^{*} \approx 75\left(\bar{P}^{*}+\bar{Q}^{*}\right) \approx 150 \sigma P^{*}
\end{aligned}
$$

Recall that the number of males and females is supposed to be the same. Combining (10-a) and (10-b) we get:

$$
g_{1}^{*} \approx 200 \sigma P^{*} \quad(10-\mathrm{c})
$$

According to data collected at the MSDR (Queiroz, 2000) the average number of fertilized eggs in the population of reproductive animals annually can be estimated as $g_{1}^{*} \approx 438 \beta \sigma P^{*}$, where $\beta$ is the fraction of successful mating among all the possible mating pairs. Comparing this relation with $(10-\mathrm{c})$ we find $\beta \approx 0,46$, meaning that from the total number of possible breeding opportunities only $46 \%$ actually happens. This estimation is confirmed by field observations.

Now from $(5-a)$ and $(5-b)$ with $h\left(P^{*}\right)=0$ it is easy to derive:

$$
\begin{aligned}
& \frac{g_{1}^{*}}{g_{2}^{*}} c_{1}=m_{2}+c_{2} \\
& c_{2}=\frac{2 m_{3} m_{2}}{c_{1} \frac{g_{1}^{*}}{P^{*}}-2 m_{3}}
\end{aligned}
$$

With (10-a) the equation (11-a) can be rewritten as $1,35 c_{1}=m_{2}+c_{2}$. The recruiting rate from fertilized eggs to larvae can be estimated to be 0,1 from field observations. Now it is expected that $c_{2}<<m_{2}$ and we may write within the range of approximation considered here $m_{2} \approx 0,135$ Introducing this value of $m_{2}$ in (11-b) and taking into account that $g_{1}^{*} \approx 200 \sigma P^{*}$ as given by $(10-\mathrm{c})$ we obtain:

$c_{2} \approx \frac{0,27 m_{3}}{200 \sigma c_{1}-2 m_{3}}$

Finally since $200 \sigma c_{1}>2 m_{3}$ the following relation holds: $c_{2} \approx \frac{00135}{\sigma} m_{3}$

In Table 1 below are shown the values of $c_{2}$ corresponding to $m_{3}$ varying in the range $[0,1-0,3]$ for an expected lifespan equal 15 years and, consequently, $\sigma=10$.

Table 1 - Variation of $c_{2}$ with $m_{3}$ for $\sigma=10$.

\begin{tabular}{llllll}
\hline $\mathrm{m}_{3}$ & 0,10 & 0,15 & 0,20 & 0,25 & 0,30 \\
$\mathrm{c}_{2}$ & 0,00014 & 0,00020 & 0,00027 & 0,00034 & 0,00041 \\
\hline
\end{tabular}

There is not enough information about $m_{1}$ from field observations. It is possible however to estimate the values of this parameter from the equilibrium condition given by equation (6-b). It is expected that close to the equilibrium point under ideal environmental conditions the fish population fall close to the carrying capacity $k$, that is:

$$
P^{*} \approx(1-\delta) \frac{k}{2} \text { where } \delta<<1
$$

With this expression together with $\mathrm{m}_{2} / \mathrm{c}_{2} \approx 10^{3}$ and $m_{3} \approx 0,1$ obtained from the previous calculations and recalling that $\delta$ is a small parameter, the equation (6-b) gives:

$m_{1} \approx 0,0002 k a \delta$ 
From the definitions of $a$ and $k$ it is easily obtained $a k=2 \sigma^{2} P a_{1} a_{2}$. Now $\bar{P} a_{1}=\sigma P a_{1}$ is the probability of egg's fertilization by all mature males and $a_{2}$ is the number of eggs spawned by females in one breeding season. Research carry out at the Mamirauá Sustainable Development Reserve reports that $a_{2} \approx 40000$. The probability $\bar{P} a_{1}$ can be estimated as $5 \%$. With $\sigma=10$ we finally obtain $a k \approx 40000$ and therefore: $m_{1} \approx 8 \delta$

A stationary fish population falling within the range $85 \%$ to $95 \%$ of the carrying capacity keeps the variation of $\delta$ in the interval $0,05 \leq \delta \leq 0,15$ leading to the correlated mortality rate $0,4 \leq m_{1} \leq 1,2$.

The estimated value for $m_{1}$ introduced in the following simulations is 0,8 consistent with these bounds.

It is important to remark that the values estimated for the parameters may vary within a relatively large interval. The range of variation for some parameters may be narrowed as field observations progress. However there is strong evidence that depending on physical and biological factors some of the parameters may indeed present a relatively large fluctuation interval. The model as presented here is robust, meaning that it is not extremely sensitive to parameters variations within acceptable intervals. One of the reasons for this lies on the fact that $a=\sigma^{2} a_{1} a_{2}$ works as a control parameter and may adjust the model output to the observable population dynamics providing an indirect measure for $a_{1} a_{2}$.

Several simulations were performed using the MAPLE computer code. The solution of the system of differential equations was obtained with the fourth order Runge Kutta numerical scheme.

We have selected three representative simulations considering that there is no expressive mortality due to lack of parental care as explained above. The parameters corresponding to the three cases $\mathrm{A}, \mathrm{B}$ and $\mathrm{C}$ are displayed in the Table 2.

Table 2 - Parameters to the cases A, B and C.

\begin{tabular}{lccccccc}
\hline Case & $\mathrm{C}_{1}$ & $\mathrm{~m}_{1}$ & $\mathrm{C}_{2}$ & $\mathrm{~m}_{3}$ & $\mathrm{~m}_{2}$ & $\mathrm{k}$ & $\mathrm{a}$ \\
\hline $\mathrm{A}$ & 0.10 & 0.80 & 0.00014 & 0.10 & 0.135 & 40 & 965 \\
$\mathrm{~B}$ & 0.10 & 0.80 & 0.00027 & 0.20 & 0.135 & 40 & 1002 \\
$\mathrm{C}$ & 0.10 & 0.80 & 0.00014 & 0.10 & 0.135 & 100 & 386 \\
\hline
\end{tabular}

For the case A the carrying capacity was taken equal to 40 . Since the $\sigma=10$ the lake is supposed to support around 400 adult fishes belonging to 10 successive cohorts.

For the case $\mathrm{B}$, the carrying capacity is the same as for case A. The coefficients $c_{2}$ and $m_{3}$ are higher than those adopted for the case A. This means that the transfer rate from larvae to adult fishes is higher for this case and the adult fish mortality as well. The value of $a$ was adjusted to set the number of adult fishes at the stable equilibrium point $P_{3}^{*}$ equal for both systems.
The carrying capacity of the lake for the case $\mathrm{C}$ is twice as much as that for the case $\mathrm{A}$ otherwise the two simulations are equal.

The points of equilibrium obtained by setting the left and side of the system (9) equal zero are displayed in the Table 3.

Table 3 - Fertilized eggs $g_{1}^{*}$, larvae $g_{2}^{*}$ and adult fishes $\mathrm{P}^{*}=\mathrm{Q}^{*}$ populations at the equilibrium points for the three typical cases $A, B$ and $C$.

\begin{tabular}{cccccc}
\hline Case & $\begin{array}{c}\text { Points of } \\
\text { equilibrium }\end{array}$ & $g_{1}^{*}$ & $g_{2}^{*}$ & $\mathrm{P}^{*}=\mathrm{Q}^{*}$ & $\begin{array}{c}\text { Type of } \\
\text { equilibrium }\end{array}$ \\
\hline \multirow{4}{*}{ A } & P1 & 0 & 0 & 0 & Stable: node \\
& P2 & 3680 & 2857 & 2 & Unstable: saddle \\
& P3 & 34740 & 25710 & 18 & Stable: focus \\
\hline \multirow{4}{*}{ B } & P1 & 0 & 0 & 0 & Stable: node \\
& P2 & 4010 & 2964 & 2 & Unstable: saddle \\
& P3 & 36080 & 26670 & 18 & Stable: focus \\
\hline \multirow{2}{*}{ C } & P1 & 0 & 0 & 0 & Stable: node \\
& P2 & 9650 & 7143 & 5 & Unstable: saddle \\
& P3 & 86850 & 64290 & 45 & Stable: focus \\
\hline
\end{tabular}

The solutions for the three cases show consistently that the first and third equilibrium points are stable. The second equilibrium point is unstable. Populations close to this point may deviate towards paths leading to extinction.

Let us consider the case A more closely. The distance between the stable equilibrium $\mathrm{P}_{3}$ close to the saturation point with approximately 36 adult Arapaima - males plus females - belonging to the same generation and the unstable equilibrium, 4 adult Arapaima, is large enough to represent a serious threatening to the population. So in principle adequate management of fishing activity could be implemented securely.

The picture of some trajectories for particular initial conditions helps to understand the population dynamics. As shown in the figure 3 , for a sufficient large initial number of larvae or eggs the trajectories pack into a thin bundle that winds up toward the stable equilibrium P3.

For an insufficient number of eggs or larvae the trajectories converge to the origin, that is, to the extinction point $\mathrm{P} 1$. The basins generated by the attractors $\mathrm{P} 1$ and $\mathrm{P} 3$ are difficult to visualize since the solution belongs to a three dimensional space. The projections of the trajectories on the $\mathrm{Pxg}_{2}$ plane are easier to follow and clarify the main qualitative aspects of the solution.

The projections of the phase space trajectories on the $\mathrm{Pxg}_{2}$ plane and the time variation of the Arapaima adult population are shown in the figures 4-a and 4-b respectively. The bulky lines in the figure 4 represent the separatrices dividing the plane $\mathrm{Pxg}_{2}$ into four regions.

Under undisturbed natural conditions the population approaches the carrying capacity of the lake provided that 

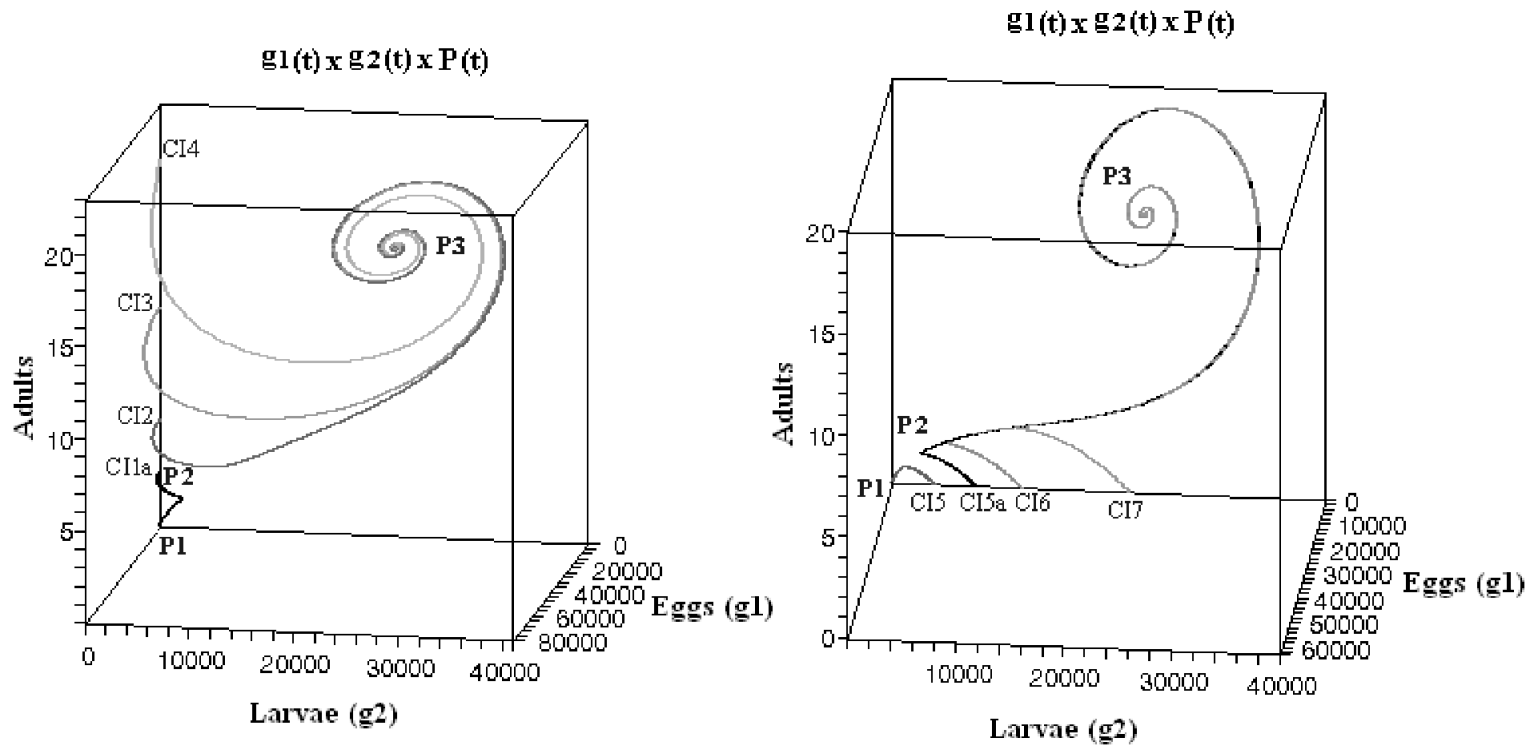

Figure 3 - Trajectories in the phase space for initial conditions: (a) $g_{1}=P=0$ and $g_{2} \neq 0$ and (b) $g_{2}=P=0$ and $g_{1} \neq 0$
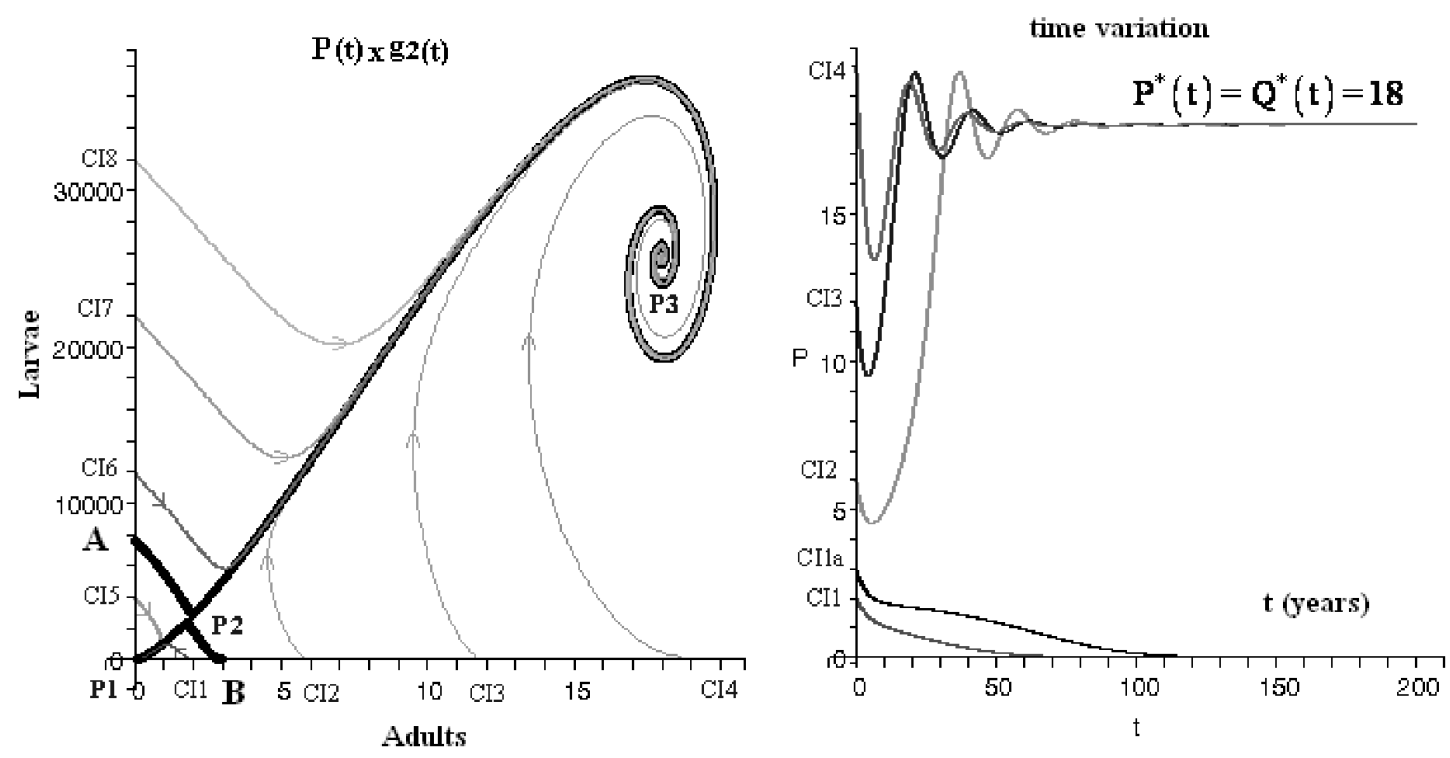

Figure 4 - Case A. Projection of the phase space on the plane $P \times g_{2}$ (a) and time variation of the mature fish populations (b)

the initial condition is at the right side of the separatrix A-B. Initial conditions $\mathrm{CI} 2, \mathrm{CI} 3, \mathrm{CI} 4$ located on the horizontal axis represent test conditions where initially the lake population consists only of adult fishes. For the other test conditions CI6, CI7, CI8 located on the vertical axis, adults Arapaima are excluded, the population at $\mathrm{t}=0$ consists of larvae/postlarvae only. The trajectories corresponding to both cases are consistent with the expected behavior. After an initial decrease in the population of adult fishes or larvae/post-larvae, the system recovers the positive feedback cycle (eggs)-(larvae/ post-larvae)-(adult fishes)-(eggs) and the population converges towards the stable equilibrium point $\mathrm{P}_{3}$.

It is also worth pointing out that the equilibrium point $P_{1}$ corresponding to extinction is a stable node. This means that the trajectories leading to extinction, CI1 or CI5 for instance, do not orbit around the origin which would be a serious drawback since in that case the trajectories would go through a region with negative populations.

The trajectories on the phase plane are similar for the cases $\mathrm{B}$ and $\mathrm{C}$ and the same conclusions are also applicable to these two cases. 
Several others tests were tried allowing the parameters to vary in a range bounded by values consistent with field observations and biological plausibility. The system has proved to be robust presenting no remarkable singular behavior. The responses vary within expected limits in the right direction according to field reports.

The model defined by (9) with the parameters belonging to the neighborhood of the values determined above is valid for lakes where nearly ideal environmental conditions prevails. It can now be extended to examine the effects of perturbations coming from several origins. We will examine in the following section the perturbation effect caused by a peculiar behavior of this species.

\section{THE EFFECT OF INEFFECTIVE MALE'S GUARDING.}

Peculiar to this species is the male concern about the safe growth of the offspring. Just after the eggs are fertilized, males start to guard the nests. But it is only after eggs hatch into larvae that males perform the careful surveillance typical of the species, to avoid the action of predators that could endanger the survival and growth of the larvae/post-larvae into juveniles Arapaima. Failure to care properly for the offspring originated by disturbance from fishing activities, for instance, will have a direct effect on the population dynamics. The system (4) considers the effect of the male's parental care through the term $\bar{h}(P) g_{2}$ in (4-b).

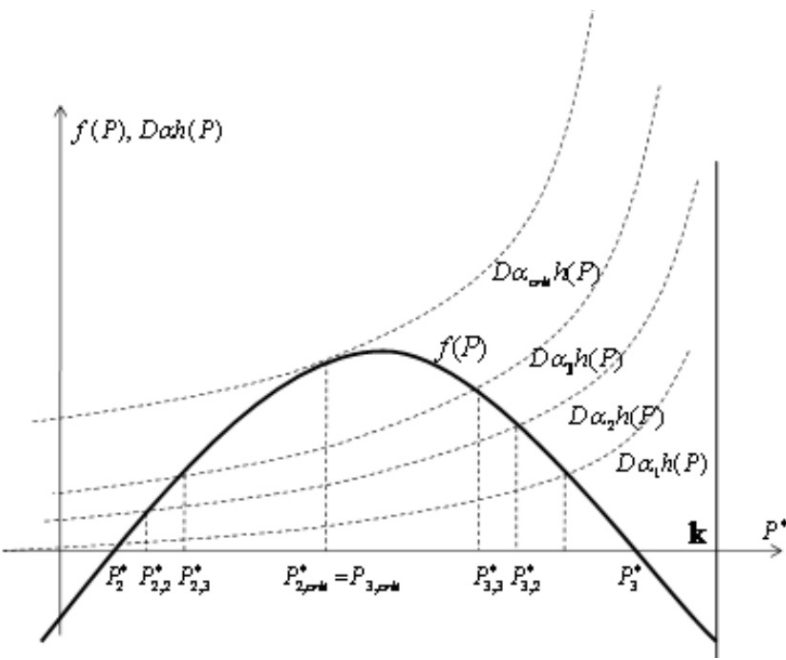

Figure 5 - Roots of equation (6a) corresponding to the points of equilibrium $P_{2, i}{ }^{*}=Q_{2, i}{ }^{*}$ and $P_{3, i}{ }^{*}=Q_{3, i}{ }^{*}$ including males' surveillance failure measure by $\alpha_{i}$

The two non-trivial equilibrium points are obtained by solving equation (6-a). Figure 5 illustrates the geometric determination of the solution. Clearly the roots correspond to the intersection of the curves $f(P)$ and $D \alpha h(P)$. The parable $f(P)$ and the curve $\operatorname{D\alpha h}(P)$ are given by the expressions on the right- and left-hand sides of equation (6-a) respectively:

$$
\begin{aligned}
& f(P)=-(P)^{2}+\frac{k}{2} P-\frac{k}{2 a}\left(1+\frac{m_{1}}{c_{1}}\right)\left(1+\frac{m_{2}}{c_{2}}\right) m_{3} \\
& \operatorname{D\alpha h}(P)=\frac{k}{2 a} \frac{m_{3}}{c_{2}}\left(1+\frac{m_{1}}{c_{1}}\right) \bar{h}(P)
\end{aligned}
$$

Clearly

$$
D=\frac{k}{2 a} \frac{m_{3}}{c_{2}}\left(1+\frac{m_{1}}{c_{1}}\right) \text { and } \bar{h}(P)=\alpha h(P)
$$

The parameter $\alpha$ indicates the degree of the surveillance failure. The higher the value of $\alpha$, the worst is the male protection of the larvae. The function $h(P)$ has to fulfill three important conditions:

1. $D \alpha h(P)$ must intercept the parable $f(P)$ at two and only two points comprised within the interval $\left\{P_{2}^{*}, P_{3}^{*}\right\}$. Note that $P_{2}^{*}, P_{3}^{*}$ are the equilibrium points for $\alpha=0$,

2. $D \alpha h(P)>0$ for all $P$, otherwise inability in the surveillance task would contribute to larvae growth which is a contradiction,

3. $\lim _{P \rightarrow k / 2}[D \alpha h(P)] \rightarrow \infty$ because it is reasonable to expect that if all males are unable to care for the offspring the collapse is catastrophic.

A satisfactory expression for $h(P)$ is:

$$
\begin{gathered}
h(P)=\frac{1}{(P-k / 2)^{2}} \\
\frac{d g_{1}}{d t}=a_{1} a_{2} P Q\left(1-\frac{P+Q}{k}\right)-c_{1} g_{1}-m_{1} g_{1}
\end{gathered}
$$

$$
\frac{d g_{2}}{d t}=c_{1} g_{1}-\frac{\alpha}{(P-k / 2)^{2}} g_{2}-c_{2} g_{2}-m_{2} g_{2}
$$

$$
\frac{d P}{d t}=\frac{1}{2} c_{2} g_{2}-m_{3} P
$$

The system (4) can be now rewritten as:

We have assumed again equal number of females and males in the Arapaima population for sake of simplicity. This hypothesis requires the quantities of males and females captured by fishing to be the same.

The non-trivial equilibrium points $\mathrm{P} 2$ and $\mathrm{P} 3$ are the roots of the transcendental equation (6-a).

Meaningful simulation now involves the variation of $\alpha$ to analyze how this parameter interferes in the population 
profile. Let us take as reference the case $\mathrm{C}$ introduced in the previous section. Using the same set of parameters and solving the system (14) for $\alpha=30$ and $\alpha=100$ we obtain the solutions

Table 4 - Variation of the population segments for three values of $\alpha$ reflecting the male surveillance effectiveness.

\begin{tabular}{cccccc}
\hline & & $g_{1}^{*}$ & $g_{2}^{*}$ & $\mathrm{P}^{*}=\mathrm{Q}^{*}$ & Type of equlibrium \\
\hline \multirow{4}{*}{$\alpha=0$} & P1 & 0 & 0 & 0 & Stable: node \\
& P2 & 9650 & 7143 & 5 & Unstable: saddle \\
& P3 & 86850 & 64290 & 45 & Stable: focus \\
\hline \multirow{4}{*}{$\alpha=30$} & P1 & 0 & 0 & 0 & Stable: node \\
& P2 & 12130 & 8065 & 6 & Unstable: saddle \\
& P3 & 154600 & 52000 & 36 & Stable: focus \\
\hline \multirow{3}{*}{$\alpha=100$} & P1 & 0 & 0 & 0 & Stable: node \\
& P2 & 20260 & 10640 & 7 & Unstable: saddle \\
& P3 & 151900 & 41630 & 29 & Stable: focus \\
\hline
\end{tabular}

shown in Table 4. The respective projections of the trajectories on the $\mathrm{Pxg}_{2}$ plane are depicted on the Figure 6.

The types of stability for the three equilibrium points for $\alpha$ $\leq 100$ are unchanged. As $\alpha$ increases, the number of Arapaima reaching maturity decreases as a consequence of lack of proper care in the earlier stages. The number of fishes at the saddle point $\mathrm{P} 2$ on the contrary increases. Far from being a favorable scenario a large number of fishes at the neighborhood of an unstable point of equilibrium may disguise an unaware observer who could think that a relatively high number of individuals would avoid a quick collapse towards extinction. In other words the attraction basin induced by P3 shrinks. The size of this attraction basin is determinant for the global stability of the system rather then the number of fishes.

Therefore the measure of the risk is not the distance to extinction $\left(g_{1}^{*}=0, g_{2}^{*}=0 P^{*}=Q^{*}=0\right)$ but the distance between the non trivial stable equilibrium population P3 and the unstable equilibrium population P2 which can be considered as a measure of the diameter of the attraction basin. For the present case the population at the unstable equilibrium point $\mathrm{P} 2$ increases from 5 , when the male care is most effective, to 15 when $\mathrm{P} 3$ and $\mathrm{P} 2$ practically coincide which corresponds to the annihilation of the attraction basin forecasting a catastrophic collapse. This scenario comes up when $\alpha \approx 220$ corresponding to the critical surveillance level $\alpha_{\text {crit }}$. Therefore the population does not decrease steadily from 45 to zero going to extinction. It decreases from 45 to 15 when the system collapses and tends inevitably to extinction.

The reduction of the attraction basin diameter given by the approximation between the points $\mathrm{P} 2$ and $\mathrm{P} 3$ with increasingly values of $\alpha$ is shown clearly in the Figure 7. For the particular value of $\alpha=\alpha_{\text {crit }}$ that brings the curve $D \alpha h\left(P^{*}\right)$ tangent to the parable $f\left(P^{*}\right)$ - see Figure 5 - the two points coincide and
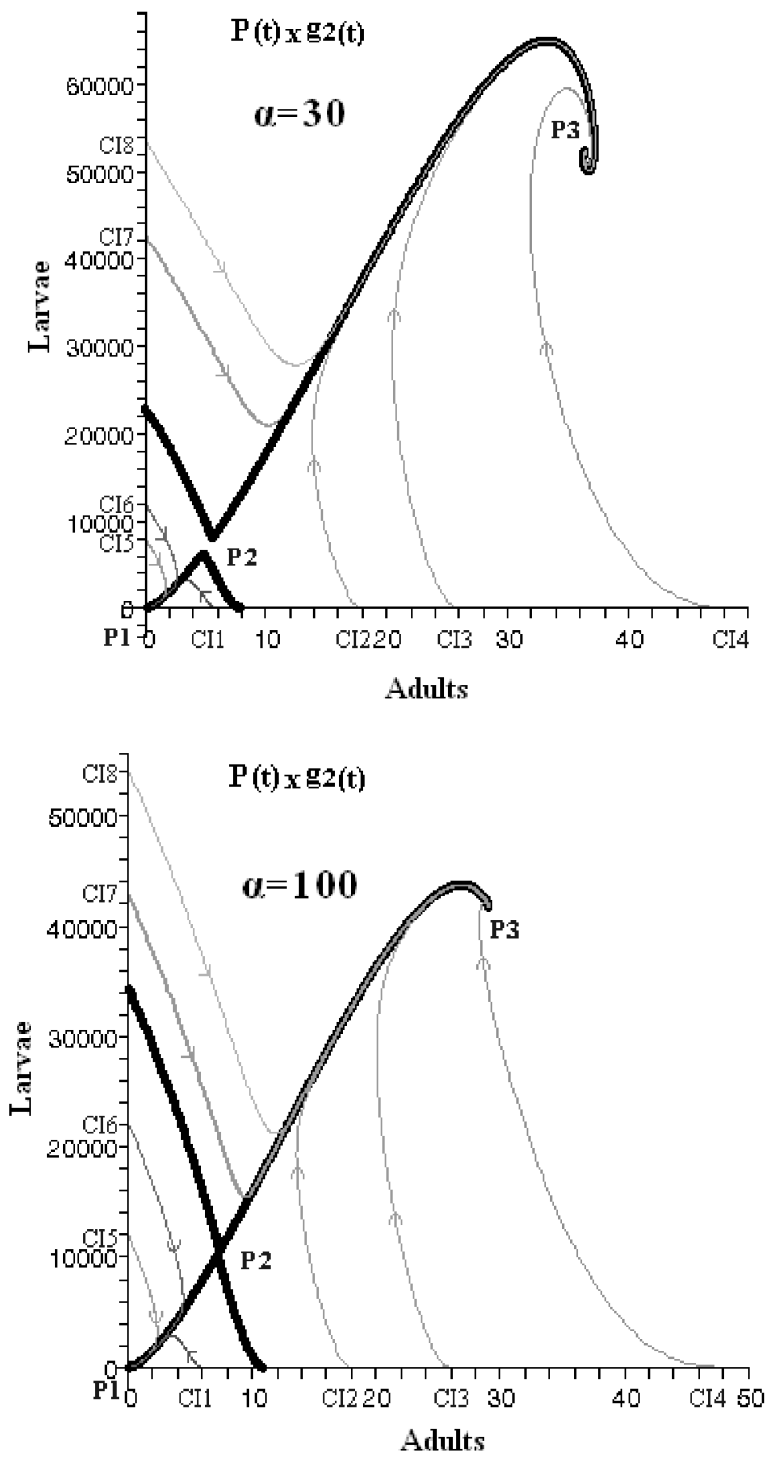

Figure 6 - Projection of the phases space trajectories on the plane $\mathrm{P} x \mathrm{~g} 2$ corresponding to increasingly failure in parental care indicated by $\alpha=30$ and $\alpha=100$

$P_{2}^{*}=P_{3}^{*}$ and the only stable point in the system is the trivial solution $P_{1}^{*}=0$ corresponding to extinction.

Another very interesting outcome of the model concerns the fertilized eggs variation with the parameter $\alpha$. The variable $g_{1}^{*}(\alpha)$ related to the stable equilibrium point at $\mathrm{P} 3$ has a maximum for $\alpha \approx 60$. From the mathematical point of view this is not surprising; it is a well known behavior which comes frequently associated to a turning point.

The biological significance is however surprisingly. As $\alpha$ increases it is expected that the quantity of larvae/post-larvae and consequently the quantity of adult fishes decrease. This expected result is confirmed by the model output as indicated 


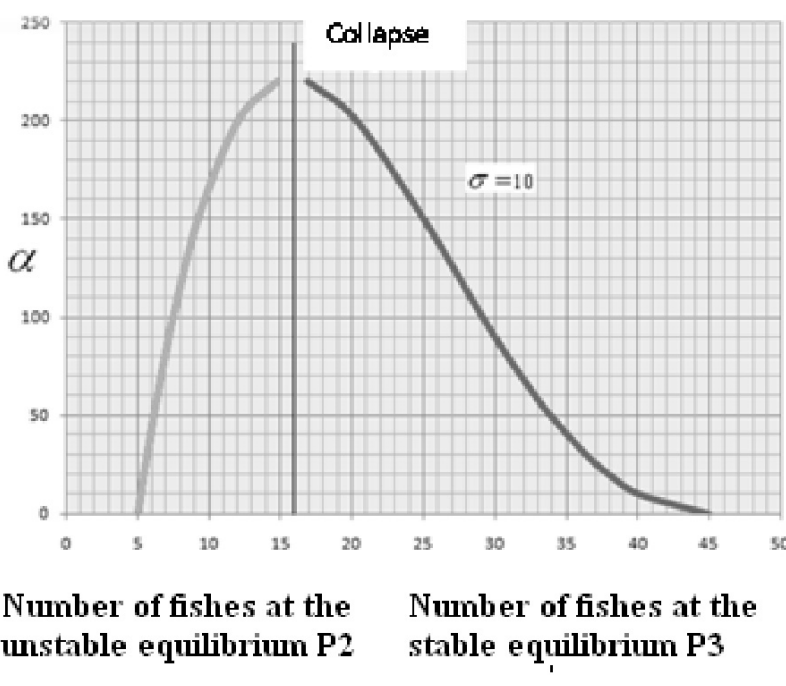

Figure 7 - Extinction threshold as functions of the parameter $\alpha$ from table 5

in Table 5. The variation of the number of fertilized eggs would in principle follow the same tendency. However the scenario disclosed by the model doesn't confirm this hypothesis. The quantity of fertilized eggs $g_{1}^{*}$ at the non trivial stable equilibrium point $\mathrm{P} 3$ initially increases with increasing values of $\alpha$. In other words, the model suggests that the lack

Table 5 - Variation of the population levels at the equilibrium points P2 and P3 with the parameter $\alpha$.

\begin{tabular}{lcccccc}
\hline & \multicolumn{3}{c}{ Point of equilibrium P3 } & \multicolumn{3}{c}{ Point of equilibrium P2 } \\
\cline { 2 - 7 }$\alpha$ & $P_{3}^{*}$ & $g_{1}^{*}$ & $g_{2}^{*}$ & $P_{2}^{*}$ & $g_{1}^{*}$ & $g_{2}^{*}$ \\
\hline 0 & 45 & 86850 & 64290 & 5 & 9650 & 7143 \\
10 & 40.13 & 136300 & 57330 & 5.2 & 10420 & 7441 \\
20 & 38 & 148700 & 54280 & 5.4 & 11250 & 7748 \\
\hline 30 & 36.4 & 154600 & 52000 & 5.64 & 12130 & 8065 \\
50 & 33.89 & 158700 & 48420 & 6.1 & 14060 & 8731 \\
60 & 32.83 & 158700 & 46890 & 6.35 & 15130 & 9082 \\
80 & 30.90 & 156400 & 44140 & 6.88 & 17510 & 9828 \\
100 & 29.14 & 151900 & 41630 & 7.45 & 20260 & 10640 \\
150 & 25.01 & 134100 & 35730 & 9.19 & 29550 & 13130 \\
200 & 20.32 & 105100 & 29030 & 11.98 & 46780 & 17110 \\
220 & 16.89 & 81040 & 24130 & 14.73 & 65660 & 21050 \\
\hline
\end{tabular}

of parental care might trigger a population response to avoid the decrease in the recruitment to the next period.

This tendency persists up to a value of $\alpha \approx 60$, as depicted in the Figure 8, when the number of eggs reaches a maximum. After that, the number of fertilized eggs follows the general tendency and starts to decline.

We believe that this unexpected result can translate a process of natural resilience frequently encountered in nature,

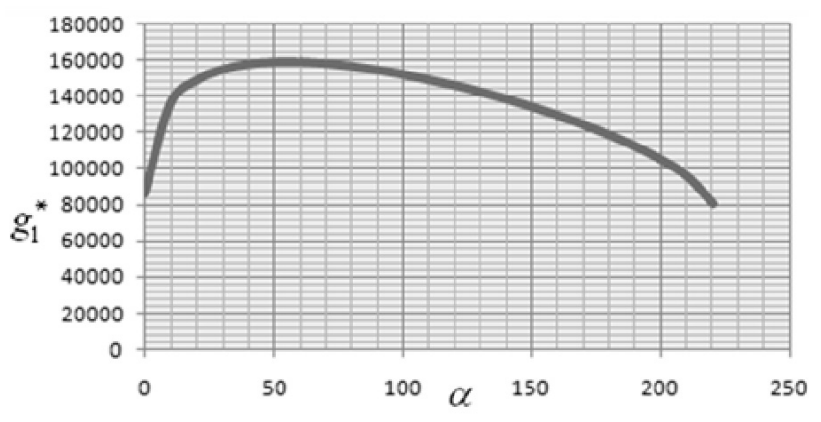

Figure 8 - Variation of the number of eggs as function of $\alpha$

but yet to be adequately investigated in further field and modeling research.

\section{CONCLUDING REMARKS}

Mathematical models hardly represent the real world (Epstein 2008). Indeed, the massive number of variables involved, as its random nature and the implicit uncertainty disturbing the interrelation among them are almost insurmountable obstacles to simulate complex biological phenomena (Faugeras et al., 2007; Niwa 2007; Jiao,Y et al., 2009; Moeller 2004; Cogdell, 2004; Turchin, 2003; Thieme, 2003; Ross 1995; Hofbauer J.,1998).

The perspective of the mathematical model adopted in the present paper is to serve as an useful tool that simulates the most important aspects of a natural phenomenon and can be used:

1. To guide the elaboration of control rules and management policies to foster the conservation of biodiversity and natural resources,

2. To indicate adequate interventions and timely actions in the fisheries of pirarucu currently promoted in the Amazon (Viana et al., 2004 and 2007) to avoid serious disasters,

3. To detect possible deviations in the current natural environment due to unexpected or hidden perturbations that may affect the populations of this species.

The system representing the population dynamics of Arapaima proposed here matches the main field observations available and reliable (Queiroz, 1997; Queiroz \& Sardinha, 1999; Queiroz, 2000; Castello, 2004; Godinho et al.,, 2005; Castello, 2008a; Castello, 2008b).

Ongoing research at the Mamirauá Sustainable Development Reserve will certainly add very important information to improve the set of dynamic equations. On the other hand the parameters introduced to develop the 
model can provide clues to explore additional observations that otherwise would be disregarded.

Direct observations that could help tuning the values of $c_{1}$ and $c_{2}$ would be of great help. We think that the parameter $a_{1}$ related to the probability of eggs fertilization by males is very difficult to be determined. But $a_{2}$ can be determined with a good approximation and if the carrying capacity is known, which is not impossible, the value of $a_{1}$ can be estimated as shown before. Validation of biological models is always difficult because the intervention on the system is very limited. New probabilistic and computational techniques are being developed that can help improve the parameter estimation of the analytical models (Masterton-Gibbons, 1995; Raol et al., 2004).

We believe however that the most intriguing result obtained above concerns the impacts of failure of male's parental care over the larvae survivorship. Two remarkable outcomes are to be highlighted from the present analysis:

1. The route to extinction is not a continuous process that could be stopped at any time. After a steadily decrease in population a critical point is reached. If the population decreases a little step further there will be no possible recovery, and a collapse will come in consequence.

2. The model exhibits moderate resilience in the presence of unsuccessful parental care. That is, if the amount of expected larvae $g_{2}$ tends to decrease, the quantity of eggs $g_{1}$ spawned increases, presumably to induce a higher rate of fertilization. The model responds according to this mode only up to a given pressure level. If the adult population falls down below this level than the path towards extinction is unavoidable.

Concerning the first observation, it is clear that if some procedure to recover the favorable conditions for the population to grow is to be taken, this should occur before the adult population reaches the critical point P2. After that, nothing can avoid collapse (as illustrated in Figure 7), except with extraordinary and probably very expensive actions. We believe that this behavior of the population, anticipated here by the model, is quite plausible. If the management authority in charge of the fisheries is not aware of this behavior, possibly unsatisfactory or misleading policies regarding fishing, for instance, could be enforced.

Simulations - see Figures 4 - performed with several initial conditions indicate that it would take about 50 years to reach the steady state - maximum number of adults compatible with the carrying capacity - starting with an adult population circa
$25 \%$ of the total corresponding to a single generation. This is ten times longer than the period to recovery and stabilization predicted before based solely in more conventional models (Queiroz \& Sardinha, 1999). Even considering all the limitations of the model this is an indication that cannot be ignored. Inadequate fisheries practices can lead to adverse conditions (to the fish population and to the surrounding environment) that would require a long time to be recovered.

The second observation reflects, as a matter of fact, an analytical outcome. If the real world responds in the same way it has to be verified. Whether females try to mitigate the effect of external threatening increasing the number of eggs dropped in the reproductive season or if exists some unknown mechanism that prevents the population to decrease is an open question. Recovering of fish population however has been reported (Hutchings J.A. et al., 2009) which is an encouraging finding to pursue more detailed field observations.

According to the response of the dynamical system the tendency to revert the population decline persists till a given failure intensity defined by the value of $\alpha$. Beyond this critical value, when the reaction reaches a maximum, there is a reversion in the tendency to avoid the collapse. This behavior raised by the model far from being discarded should be further examined. Anyway this hypothesis could hardly be anticipated without the help of the analytical result. This is another example that models, even incorporating some simplified assumptions, contribute to the advance of field research.

Finally we should point out that this paper was written in order to outreach a broad audience and to provide some practical insight into the Arapaima population dynamics. Mathematical details were left aside and can be found elsewhere (Cassiano et al., 2007). The main focus was to implement a dynamic system and adjust the parameters to fit field observations.

The improvement of this model can only be made through a continuous interaction between people with predominant biological expertise and people with predominant applied mathematics expertise.

\section{ACKNOWLEDGEMENTS}

This research was supported by the GEOMA project partly funded by FINEP/MCT and the National Research Council (CNPq/MCT). We are indebt with the technician and research teams working at Mamirauá Sustainable Development Reserve, as well as the local fishermen, for their invaluable help in selecting the data needed to carry on this research. 


\section{LITERATURE CITED}

Arantes, C. C., Castello, L. \& Garcez, D. S. 2007. Counting discrepancies of Arapaima gigas (Schinz) (Osteoglossomorpha, Osteoglossidae) performed by individual fishermen in Mamirauá, Brasil, Pan-American Journal of Aquatic Sciences 2 (3): 263-269 (in Portuguese).

Cassiano J., Bevilacqua L.2007. A study on bifurcations in the pirarucu population dynamics, Congresso da Sociedade Latino-americana de Biologia Matemática, XIV CLAB e IX ELAEM. (in Portuguese).

Castello, L.( 2004). A method to count pirarucu Arapaima gigas: fishers, assessment and management. North American Journal of Fisheries Management 24: 379-389.

Castello, L.(2008a). Lateral migration of Arapaima gigas in floodplains of the Amazon. Ecology of Freshwater Fish 17(1):38-46.

Castello L. (2008b). Nesting habitat of Arapaima gigas (Schinz) in Amazonian floodplains. Journal of Fish Biology 72, 1520-1528.

Cogdell, J.R.(2004). Modeling Random Systems. Pearson/Printice Hall.

Edelstein-Keshet, L.(1998). Mathematical Models in Biology. MacGraw Hill.

Epstein J.M. (2008). Why Model?. Keynote address to the Second World Congress on Social Simulation, George Mason University.

Faugeras B., Maury O.,(2007) Modeling Fish Population movements: From an individual-based representation to an advection-diffusion equation, Journal of Theoretical Biology 247, 837-848

Fontenele, O. (1948). Contribution to the knowledge of the pirarucu biology, Arapaima gigas (Cuvier), in captivity (Actinopterygii, Osteoglossidae), Ver. Brás. Biol. 8 (4): 445-459. (in Portuguese).

Fontenele, O. (1953). Pirarucu's spawning habits, Arapaima gigas (Cuvier) (Pisces: Isospondyli, Arapaimidae), and larvae growing process. DENOCS Publ. N. 153 ser. I-C. Fortaleza, 22pp, 1953.

Godinho, H.P., Santos, J.E., Formagio, P.S. , Guimarães-Cruz., R.J. (2005). Gonadal morphology and reproductive traits of the Amazonian fish Arapaima gigas (Schinz, 1822). Acta Zoológica (Stockholm) 86:289-294.

Guckenheimer J., P. Holmes, (2002). Non Linear Oscillations, Dynamical Systems and Bifurcation of Vector Fields, Springer Verlag. New York.

Hirsch W.M., Smale S., Devaney R.L.(2004). Differential Equations, Dynamic Systems and an Introduction to Chaos, Elsevier Academic Press.

Hutchings J.A., Reynolds J.D.(2009). Marine Fish Population Collapses: Consequences for Recovery and Extinction Risk, ICES Journal of Marine Science 66(2), (2009) 367-377

Hofbauer J., Sigmund, K,. (1958) Evolutionary Games and Population Dynamics, Cambridge University Press.

Hrbek Tomas, Izeni P. Farias, Marcelo Crossa, Iracilda Sampaio, Jorge I. R. Porto, Axel Meyer, (2005) "Population genetic analysis of Arapaima gigas, one of the largest freshwater fishes of the Amazon basin: implications for its conservation", Animal Conservation (2005) 8, 297-308.

Imbiriba, E.P. (1994), Reproduction, larvae and post-larvae stages in pirarucu's life cycle (Arapaima gigas). Basic recommendations. 26. EMBRAPA/CPATU. Belém, PA. (in Portuguese).
Jiao, Y., Hayes, C., and Cortés, E. (2009). Hierarchical Bayesian approach for population dynamics modelling of fish complexes without species-specific data. - ICES Journal of Marine Science, 66 (2009) 367-377.

Masterton-Gibbons, M. (1995) A Concrete Approach to Mathematical Modelling, Addison-Wesley, New York

Moeller D.P.F. (2004). Mathematical and Computational Modeling and Simulation, Springer, New York.

Niwa H-S, (2007). Random-walk dynamics of exploited fish populations, ICES Journal of Marine Science, 64(3):496-502

Thieme, H.R.(2003) Mathematics in Population Dynamics, Princeton University Press

Throne J.E., Parajulee M.N., Phillips T.W. (2000). “Computer Model for Simulating Population Dynamics of the Predator Lyctocoris campestris (Heteroptera: Anthocoridae) in Stored Shelled Corn", Environmental Entomology 29(6):1236-1243.

Turchin, P.,(2003). Complex population dynamics: a theoretical/ empirical synthesis. Princeton University Press.

Queiroz, H.L. (1997). Artisanal fisheries of Pirarucu at the Mamiraud Ecological Station. In: Várzea; diversity, development and conservation of Amazonia's whitewater floodplains (Padock, C.; Ayres, M.; Pinedo-Vasquez, M.; Henderson, A. Orgs). New York Botanical Garden Press, v.13:83-100. New York.

Queiroz, H.L. \& Sardinha, A. D. (1999). Pirarucu's preservation and sustainable use at Mamirauá. Management Strategies for the fiheries resources at Mamirauá. (Queiroz, H.L. \& Crampton, W. ed's.). SCM -CNPq/ MCT. Brasília. 197 pp, 1999.

Queiroz, H.L. (2000). Natural history and conservation of pirarucu, Arapaima gigas, at the Amazonian Varrea: Red giants in muddy waters. Thesis submitted for the degree of Doctor of Philosiphy, University of St Andrews.

Queiroz, H.L. (2005). A RDSM- a model of a protected area for sustained exploration. Estudos Avançados - Dossiê Amazônia, São Paulo, v.54,n.2,p.183-204, 2005.(in Portuguese)

Raol J.R., G. Girija G., Singh J., (2004) Modelling and Parameter Estimation of Dynamic Systems, The Institution of Engineering and Technology,, London, UK.

Ross.S.M. (1995). Introduction to Probability Models, Academic Press, 1995

Viana, J. P., L. Castello, J. M. B. Damasceno, E. S. R. Amaral, G. M. B. Estupiñán, C. Arantes, G. S. Batista, D. S. Garcez, and Barbosa S.(2007). Community organized managementod pirarucu Arapaima gigas in the Mamiraua Sustainable Development Reserve, Amazonas, Brazil. In: Áreas aquáticas protegidas como instrumento de gestão pesqueira. Ministério do Meio Ambiente e IBAMA, pages 239-261 Brasília. .(in Portuguese)

Viana, J. P., J. M. B. Damasceno, L. Castello, and W. G. R. Crampton (2004). Economic incentives for sustainable community management offishery resources in the Mamiraua Sustainable Development Reserve, Amazonas, Brazil, in: K. Silvius, R. Bodmer and J.M.V. Fragoso, editors, People in nature: wildlife conservation inSouth and Central America. pages 139-154. Columbia University Press, New York.

Recebido em 14/07/2009

Aceito em 16/11/2009 
